\title{
The relationship between the antibiotic consumption in hospitals and the community and the selection of methicillin-resistant Staphylococcus aureus
}

\author{
L Kardaś-Słoma ${ }^{1,2,3^{*}}$, PY Boëlle ${ }^{1,2}$, D Guillemot ${ }^{4}$, L Temime $^{3}$ \\ From International Conference on Prevention \& Infection Control (ICPIC 2011) \\ Geneva, Switzerland. 29 June - 2 July 2011
}

\section{Introduction / objectives}

The impact of reductions in antibiotic use on the selection of antibiotic-resistant bacteria such as methicillinresistant Staphylococcus aureus (MRSA) is difficult to assess, all the more so as they are often accompanied by a concomitant increase in the use of a specific antibiotic class.

\section{Methods}

We developed a computerized model of $S$. aureus transmission in a hospital ward and in the community, where methicillin-sensitive (MSSA), community-associated MRSA (CA-MRSA) and hospital-associated MRSA (HAMRSA) strains co-circulate between these two settings. We assessed the impact of a $15-50 \%$ reduction in antibiotic use in community and hospitals, under several hypotheses regarding changes in the distribution of prescribed antibiotics.

\section{Results}

An overall reduction in antibiotic use in the community led to decreased frequency of MRSA but increased carriage of $S$. aureus in both hospital and community settings. A similar reduction in hospitals had no impact on community dynamics.

Antibiotic classes-specific changes over the time period of the reduction in global ambulatory antibiotic use had an important impact on MRSA selection in hospitals and in the community. For instance, in the hypothesis of a $15 \%$ antibiotic use reduction, the induced decrease in hospital MRSA frequency was 2.6 times less important if this was accompanied by a concomitant $30 \%$ increase in the use of quinolones.

\section{Conclusion}

Antibiotic reduction policies may not prove sufficient to decrease antibiotic-resistance frequency. They should include a surveillance of changes in the consumption of each antibiotic class.

\section{Disclosure of interest}

None declared.

\section{Author details}

${ }^{1}$ Pierre and Marie Curie University, Paris, France. ${ }^{2}$ Inserm, U 707, Paris, France. ${ }^{3}$ CNAM, Paris, France. ${ }^{4}$ Institut Pasteur,PhEMI, Paris, France.

Published: 29 June 2011

\section{doi:10.1186/1753-6561-5-S6-072}

Cite this article as: Kardaś-Słoma et al:: The relationship between the antibiotic consumption in hospitals and the community and the selection of methicillin-resistant Staphylococcus aureus. BMC Proceedings 2011 5(Suppl 6):O72.

${ }^{1}$ Pierre and Marie Curie University, Paris, France

Full list of author information is available at the end of the article

(c) 2011 Kardaś-Słoma et al; licensee BioMed Central Ltd. This is an open access article distributed under the terms of the Creative 